TACTICAL URBANISM BENEFITS AND CONSTRAINTS: A BRAMPTON CASE STUDY

\author{
by \\ Josephine Tavares \\ BA, The University of Toronto Mississauga, 2016 \\ A Major Research Paper \\ Presented to Ryerson University \\ in partial fulfillment of the requirements for the degree of \\ Master of Planning \\ in \\ Urban Development
}

- Toronto, Ontario, Canada, 2018

C Josephine Tavares 2018* 
Tactical Urbanism Benefits and Constraints: A Brampton Case Study

\section{Author's Declaration for Electronic Submission of a MRP}

I hereby declare that I am the sole author of this MRP. This is a true copy of the MRP, including any required final revisions.

I authorize Ryerson University to lend this MRP to other institutions or individuals for the purpose of scholarly research

I further authorize Ryerson University to reproduce this MRP by photocopying or by other means, in total or in part, at the request of other institutions or individuals for the purpose of scholarly research.

I understand that my MRP may be made electronically available to the public. 
Tactical Urbanism Benefits and Constraints: A Brampton Case Study

\title{
TACTICAL URBANISM BENEFITS AND CONSTRAINTS: A BRAMPTON CASE STUDY
}

\author{
(C) Josephine Tavares, 2018 \\ Master of Planning in Urban Development Ryerson University
}

\begin{abstract}
The idea of informality in spaces is not a new concept, it is employed worldwide on a regular basis from something as simple as garage sale to a food truck moving to from place to place. Tactical urbanism draws from the idea of informality, through its attractive attributes (not permanent, limited resources necessary, any interested stakeholder can implement it and more), as short term solutions to drive change within communities. This research examines one tactical urbanism intervention in Brampton, Ontario to highlight the benefits and constraints of employing this method to drive change within the city. A review of the existing literature on tactical urbanism is used to aid in this analysis, and to compare to the case example ultimately, arriving at some recommendations for future the implementation of tactical urbanism interventions.
\end{abstract}

Key words:

Tactical Urbanism, Brampton, Informality, Short term planning solutions 
Tactical Urbanism Benefits and Constraints: A Brampton Case Study

\section{Acknowledgements}

I want to thank Dr. Zhixi C. Zhuang for her guidance and support throughout this creative and challenging process. I would also like to thank Brampton's Planning Vision Team Antonietta Minichillo and Anand Balram for all of their help, being the second reader for my MRP and for being so passionate about trying to make Brampton great! 


\section{Table of Contents}

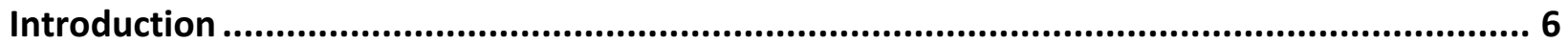

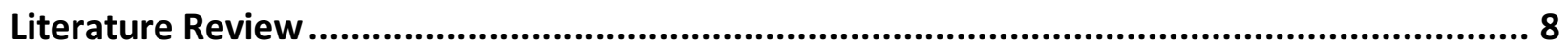

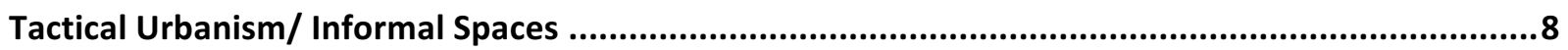

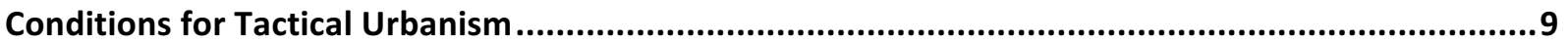

Benefits of Tactical Urbanism .........................................................................................9

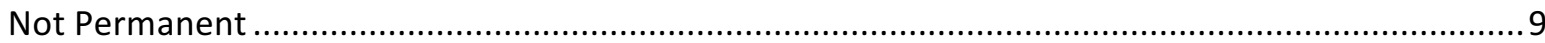

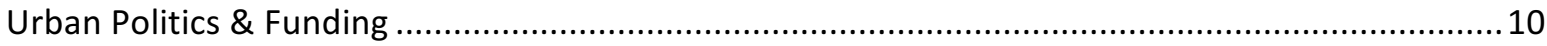

Community Involvement and Increased Participation .................................................................. 11

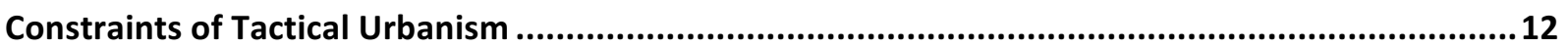

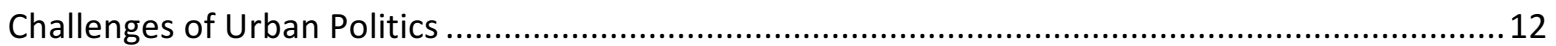

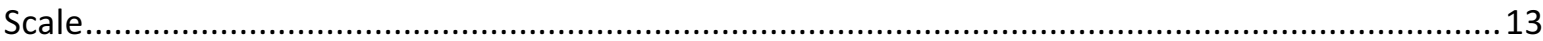

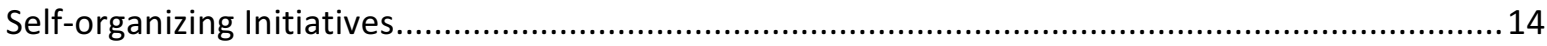

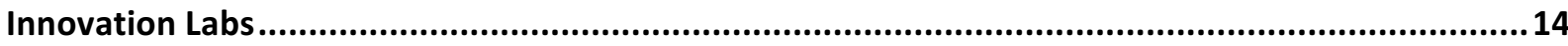

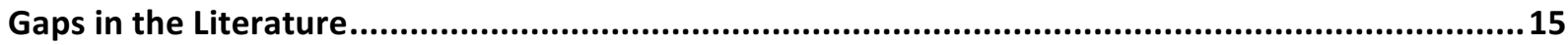

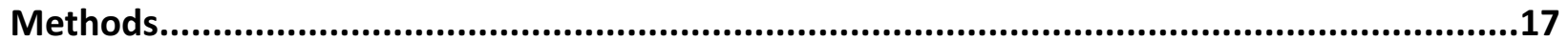

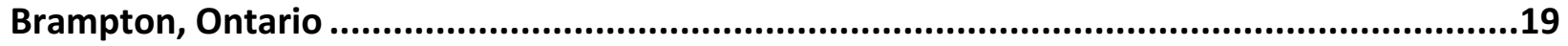

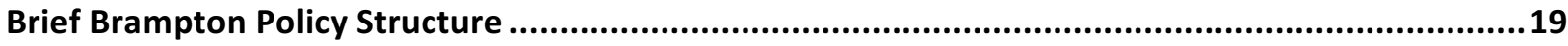

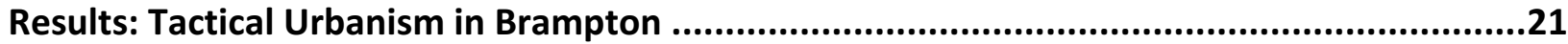

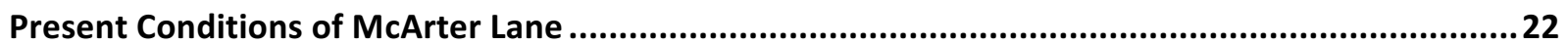

The Tactical Urbanism Intervention in Brampton..................................................................22

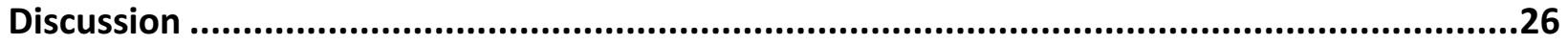

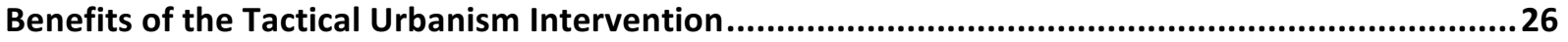

Constraints Associated with the Tactical Urbanism Intervention ...................................................27

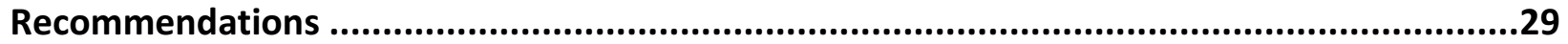

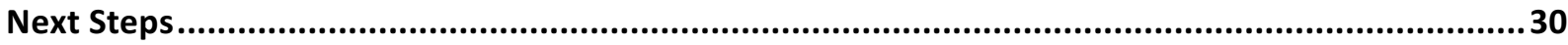

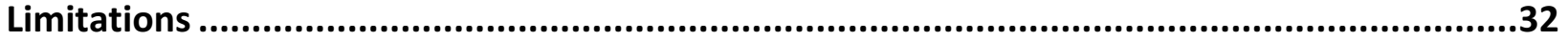

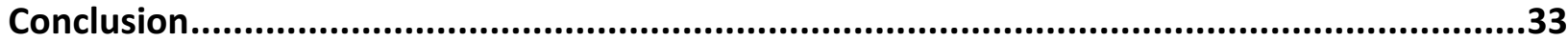

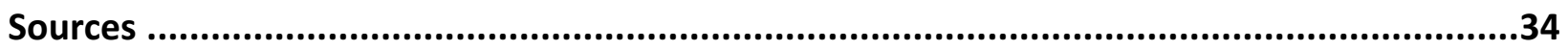

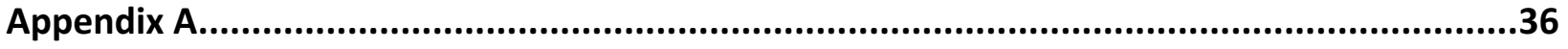

School of Urban and Regional Planning v v 


\section{Introduction}

Traditional planning models, methods, and process are typically lengthy, long term solutions and often require a lot of time and resources. In an age where cities are rapidly changing it is becoming clear that more short term solutions are required to keep up with the demands of; planners, community members, and stakeholders that are interested in driving change within their communities. Neighborhoods experience change regularly and at varying levels of speed, sometimes spaces can go unnoticed, they may be used for one purpose, they might deteriorate over time, or they may never reach their full potential. To showcase how these types of spaces can live up to their potential or how they can more effectively contribute to the community, interested stakeholders need to think creatively and outside of the box for solutions to this dilemma. One of the increasingly popular tactics that is used around the world is informal spaces or tactical urbanism interventions.

Tactical urbanism is a form of informality, it is typically a short term, pop-up intervention that usually involves the assembly of non-permanent objects or items, within unused or underutilized spaces to achieve specific objectives, such as, displaying the potential of a space (Silva, 2016). It can be implemented by community members, planners, municipalities, organization, non-for profits, or any other stakeholder with an interest in improving their neighborhood or community (Iveson, 2013). The short term, non-permanent nature of projects is an attractive aspect to many as it can often conjure conversation or buzz without a substantial amount of capital, resources or time. Tactical urbanism or informality will likely only become more popular, the role of urban planners will be to encourage and harness enthusiasm for informal spaces, by empowering citizens to contribute to the design of their surroundings (Donovan, 2014). Mould (2014), argues that tactical urbanism generates a more community oriented and usable city, informality allows for a city to become more inviting and encourages residents to engage with the urban topography. Identifying and creating the conditions that foster and strengthen a sense of community spaces within residential neighborhoods is an important task for researchers and planners alike (Francis et al. (2012). Tactical urbanism uses a temporary model, and incremental change approaches to transforming a neighborhood, which differs vastly from traditional long term planning models such as master plan larger inflexible projects

\section{School of Urban and Regional Planning}


(Németh, J. Langhorst, 2014).

This paper strives to understand how tactical urbanism can be a benefit or how it can be used as a tool that a suburban city or municipality can implement based on specific aims. Consequently, to assess how tactical urbanism or informality can be seen as a constraint with varying implications that may impede on the effectiveness. Through the use of Brampton, Ontario as a case example to apply to these concepts identified in the literature, it will become clear how tactical urbanism can be used by municipalities to drive change within their communities or neighborhoods. Specifically, Brampton is a suburban city where the implementation of tactical urbanism is not common if ever employed in this way. The findings highlight benefits such as the non-permanent nature, urban politics, increased resident participation and community involvement and the constraints include ideas such as; challenges in urban politics, scale, and self-organizing initiatives. 


\section{Literature Review}

This next section reviews the literature available on informal spaces/ tactical urbanism in urban, and public spaces, and highlights any gaps that exist that aid in the understanding and need for this paper.

\section{Tactical Urbanism/ Informal Spaces}

Mukhiia, \& Loukaitou-Sideris (pg. 295, 2014) suggest "Informality challenges a planner's rational practices and regulatory conventions". Bringing about change in cities for long standing or emerging problems can be challenging, due to policy constraints, time, resources, zoning requirements etc. Bishop and Williams (2012) argue that in this day and age of increasing pressure and limited if any resources, we need to provide quick solutions rather than wait around for long term plans that typically fall out of the traditional planning models for various spaces in our cities. Thus, the emergence of informal or temporary uses of space has become a prevalent tactic anybody can implement to drive change within a city or their community. Silva (pg. 1044, 2016) argues that "tactical urbanism is a broad expression that can be used to describe various interventions within a city such as; to correspond to different qualities, the creation of temporary use models for the reuse of a city's vacant lands, it can act as a lighter way to test solutions that would otherwise be very costly, or by drawing attention and reclaiming abandoned spaces". Similarly, Mukhiia \& Loukaitou-Sideris (2014) argues that, tactical urbanism is occurring due to a number of different reasons including; increasing immigration, economic instability, increasing unemployment and underemployment, inadequacy of existing regulations to address the complexity of contemporary multicultural living, a need to transform underutilized spaces, and there are likely many more contributing factors to consider as well. There is evidence that informality is an integral and a growing part of cities in the world (Silva, 2014, Mukhiia \& Loukaitou-Sideris, 2014, Lydon et al., 2011, 2012).

Talen (pg. 138, 2014) suggests that "Informality is the latest chapter in a long standing interest in making cities more humane, authentic, and liveable through the actions of individuals, small groups and organizations". Informal spaces are created and occur on almost a regular basis; they can include simple transformations such as hosting a garage sale on a Saturday morning or a food truck travelling from event to event (Mukhiia \& Loukaitou-Sideris, 2014). It 
is important to note that tactical urbanism or informality is not used to test or pilot large scale projects such as, bridges, skyscrapers or other large infrastructure, these kinds of projects would involve permanent solutions through careful planning and considered (Lydon \& Garcia, 2015). Lydon et al. $(2011,2012)$ suggest that most tactical urbanism initiatives tend to have a very specific time frame, and are not often made to last but as mentioned in the preceding paragraph, have specific aims. As the literature highlights the idea of pop-up or informality is largely becoming popular world-wide and should be seen as a strategic way to test ideas, drive change, improve abandoned and underutilized spaces and offer a sense of excitement and creativity amongst communities.

\section{Conditions for Tactical Urbanism}

While tactical urbanism could virtually happen anywhere in a city from a parking lot, to a laneway, to a public park (there many more places as well), Lydon et al. (pg. 3, 2012) suggests that "the best examples are consistently found in compact towns and cities featuring an undervalued and underutilized supply of walkable urban fabric". This is why most examples of tactical urbanism tend to be located in more densely populated urban areas, rather than the suburbs where walkability can often be a challenge.

\section{Benefits of Tactical Urbanism}

\section{Not Permanent}

Tactical urbanism can offer a number of different benefits to a municipality or community, one of the most appealing aspects of implementing tactical urbanism is its temporary nature. Németh, J. Langhorst (pg.146, 2013) argues that the "impacts in most tactical urbanism projects are fully reversible with no or very little effort, if physical elements are involved in the use, these tend to be removable and are not permanently attached to surfaces or structures". Thus, tactical urbanism offers a unique opportunity to change the normal without making alterations that will potentially harm or mark up the space. Furthermore, making this type of project or tactic very attractive to organizations, planners, community members, non-profits etc. to achieve their desired outcomes (Lydon \& Garcia, 2015). 


\section{Urban Politics \& Funding}

The short-term nature of tactical urbanism allows for stakeholders such as politicians, policy makers, developers, planners and other key stakeholders to see the possibility a space may have to offer a community. The successful implementation of tactical urbanism projects within a city can aid stakeholders in, creating and altering existing policies to support change within a city or community. Iveson (pg. 955, 2013) argues that "such experiments will only give birth to a more democratic city if we can find ways to politicize them". Informality serves as a means to implement and test what would otherwise be considered an expensive project. Research suggests that, tactical urbanism is a more simplistic way to test ideas on lands that too often enthusiasm and momentum wane as projects await capital budgets, grants, or state and federal funding (Lydon \& Garcia 2015; Silva 2016; Nemeth \& Langhorst 2014; and Finn 2014). Delay’s due to waiting for funds, may leads to delays in the project implementation and delivery or can even often result in permanent delays.

For example, in the small city of Penrith, Australia a consultant team pushed city council to employ a 1-year pop-up park, knowing that the money and political will for the project did not exist (Lydon \& Garcia, 2015). City council reluctantly agreed to provide $\$ 40,000$ for the project, despite some initial pushback from residents. Once the pop-up project was implemented it, eventually became a space that people became accustomed to and residents reported that they really enjoyed the regular events hosted at the park (Lydon \& Garcia, 2015). After the 1-year mark the park was permanently implemented (Lydon \& Garcia, 2015). While this project was slightly lengthier than most tactical urbanism projects, it clearly displays the impetus and importance of real life engagement with a space to help gain the support of the community members and important stakeholders, to drive change within a city.

Iveson (pg. 955, 2013) suggests that the "need for a new city or a reimagined city to emerge out of the present dysfunctional and unjust urban conditions is an urgent matter, informality is a means to achieve a more democratic city without the formal processes typically involved in planning". Silva (2014) argues that tactical urbanism can change the dynamic and structure of city planning because there would be greater interaction between local actors and public administration, both are concerned about the improving the city from different perspectives. Informality can also be beneficial for cities because, public administration is typically used to implement rather than to test ideas, thus tactical urbanism initiatives could gain 
space in the planning practice as a means to test solutions while they are being formulated and discussed (Silva, 2014).

\section{Community Involvement and Increased Participation}

Community involvement is a key driver in the success of tactical urbanism (Lydon et al., 2011), especially when trying to vision and demonstrate to the community how a space could be used or a potential proposal for the space. Tactical urbanism projects "often result from the direct participation of citizens in the creation and activation of their neighborhood or the creative work of formal entities, such as non-profits, developers, and government" (Lydon \& Garcia, pg. 6 2015). Community participation is especially important when trying to highlight to policy makers the potential of a space. If the temporary change becomes occupied and engaged by a number of people in the community, then this could display that this form of temporary change could likely become a successful permanent change. Consequently, if the pop-up is not attracting people it might not be considered an effective use of the space. Lydon et al. (pg. 1, 2011) argues a pivotal aspect of tactical urbanism is that, "citizens are typically invited to engage in the process that is, rather than being asked to contribute to incremental change residents are asked to react to the proposals". It is then the reactions and participation of the community that help to drive future change.

Tactical urbanism can also be seen as a way to get more people involved in the planning process. Lydon and Garcia (2015) recognize and argue that public planning initiatives and projects will almost never reach $100 \%$ participation however, well executed tactical urbanism projects are one way to bring planning proposals and concepts to a wider audience. Temporary variations to a space is a way that people can interact and visually understand changes in spaces they may pass by on a regular basis, rather than asking residents to come to City Hall at 6pm on a weekday and conceptually try to understand a proposal (Lydon \& Garcia, 2015). By allowing community members to visually see and engage with a space it can also help mitigate NIMBYism (not in my backyard) as fears for the possibility of change can be demonstrated in the short term (Lydon \& Garcia, 2015). Németh \& Langhorst (pg. 148, 2014) argues that "temporary uses of spaces can instill a sense of participation in the creation of a place within a community as the traditional regulatory and planning systems and rules governing land tenure excludes them from many forms of land use and occupation". Residents might feel more involved in their community when these changes occur because it encourages them to engage 
Tactical Urbanism Benefits and Constraints: A Brampton Case Study

with the urban topography and can even foster a sense of responsibility to be active citizens in their community (Mould, 2014). To this end, tactical urbanism and informality can be seen as a positive measure to help increase public participation and involvement in driving change in cities and communities.

\section{Constraints of Tactical Urbanism}

\section{Challenges of Urban Politics}

There are a number of challenges and concerns that have arisen with emergence of tactical urbanism projects within cities and communities. The first is tactical urbanism can be seen as a threat to municipalities, these types of projects often get to by-pass a lot of the red tape and regulations associated with occupying or engaging the public in spaces. Finn (pg. 382, 2014) argues, "cities may want to consider ways of mitigating potential negative impacts, and while simply ignoring or criminalizing such activities are potentially rational responses, these strategies may be too short-sighted". To this end, tactical urbanism is a cool and unique strategy that can be implemented to drive change, however, one of the main reasons why it can be seen as a threat to municipalities is that someone must be liable if something goes wrong. This is why scholars such as Finn (2014) and Iveson (2013) suggest maintaining public safety, balancing equity concerns, consensus, efficiency, coordination of urban systems and more are important aspects that need to be considered and prioritized when it comes to the temporary uses of space. Finn (2014) suggests that informality or temporary uses of space can to some degree be seen as a soft form of rebellion against traditional planning practices, which are often perceived to lack flexibility. Tactical urbanism can threaten the role of the planner, if implemented by community members. The public may see this as a way to approach the issues in their community on their own, rather than consulting the opinions of local planning officials (Finn, 2014).

Concerns such as the above mentioned (public safety, consensus etc.) might lead authorities to second guess tactical urbanism or informality and might possibility shut down any future project, if approval is not granted through a yet another formal process. Iveson (2013) argues, that these types of projects contest authorities to dictate transformed spaces, authorities might go to great lengths to monitor and prevent these projects from occurring based on concerns around public safety, equity concerns, ignoring professional planning opinions etc. For example, in Washington, DC, the Metropolitan Area Transportation Authority became the target of what 
they called the "Phantom Planter", 176 flower boxes were planted around the DuPont Circle metro station (Finn, 2014). The Transportation Authority decided to rip out all 176 flower boxes because they already allegedly had plans to beatify the space, (Finn, 2014). They threatened the person(s) behind the planting with imprisonment if caught caring for the existing plants, or caught with new plants (Finn, 2014). The public was outraged by this decision (Finn, 2014). Therefore, with the increase in popularity of tactical urbanism projects in cities, citizens might see increase in monitoring or policing.

Silva (2014) argues that another urban politics issue that arises from tactical urbanism is its potential to be used as a strategy to support more profitable endeavours. Németh \& Langhorst (pg. 148, 2014) argues "if temporary uses are suspended in favour of more profitable endeavours, defeating the hopes of communities frequently already victimized by the processes of uneven development, and conceivably disenfranchising them even further from participating in the discourses on the future of their neighborhoods". Displaying that tactical urbanism can sometimes create or facilitate uneven public benefits. Which is why Finn (2014) argues that the planning model sets out a clear role for local government, and they are responsible for managing private resources or actions to maximize public benefit. To this end, tactical urbanism at times can be seen as providing uneven benefits in local communities, whereas some communities may never see a tactical urbanism project in their neighborhood.

Lastly, while tactical urbanism can be an effective tool to show community members and stakeholders the potential of spaces in a city or community, even if successful may not always result in change. Silva (2014) argues tactical urbanism is able to demonstrate ideas around planning but it does not wait for the urban object to be built or for policy to be made following the project. To this end, tactical urbanism might start conversations within communities but unfortunately might not be implemented permanently by the necessary decision makers. Scale

Tactical urbanism often involves small scale interventions within cities or communities. Finn (2014) argues that because tactical urbanism projects are often small scale, it might be easy to overlook these efforts as mere pranks in need of better policing. Therefore, Finn (2014) additionally argues that a clear model for implementation would be a useful tool to help meaningfully implement tactical urbanism to provide input to formal municipal planning and design teams. While there is not much literature to support this idea, it is an interesting thought 
to consider when implementing or planning tactical urbanism projects in the future. Silva (2014) argues another issue tactical urbanism imposes in regards to scale is that while it is great for demonstrating how smaller spaces such as blocks, laneways, streets etc. can be great spaces again, there are many large scale problems within cities that need to evolve over time that a small scale approach can't fix

\section{Self-organizing Initiatives}

While tactical urbanism can be seen as a positive way to drive change, in order for this to happen, there must be a number of motivated community members, developers, non-profits, organizations etc. who are willing to take the task on. To implement change this often requires resources, time, and money which might not always be available or at the disposal of community members and organizations (Silva, 2014; Mould, 2014). Németh \& Langhorst (2014) argue that time is a huge factor that plays into the implementation of temporary spaces, and that time is a necessary first step, which might not be something everyone can donate. Therefore, if residents, organization, non-profits etc., are not actively advocating and pushing for changes in their neighborhoods tactical urbanism will likely not happen.

\section{Innovation Labs}

Over the past couple of years there has been some popularity around forming innovations labs to help draw attention to urban planning practices. Specifically, Edmonton has created a CITYlab that "supports and creates small, temporary projects, activities and events to test new planning ideas and advance the conversation around urban planning in Edmonton" (Edmonton CITYlab, paragraph 1, 2018). Edmonton uses informality and tactical urbanism regularly to showcase and engage in conversations about how to evolve Edmonton into a place where people can live, work, and play (Edmonton, CITYlab, 2018). Some of the projects they have employed include DIY city; "CITYlab encouraged residents to create short-term, safe, fun, place-making projects to turn underused spaces into welcoming places" and Parking day, CITYlab encouraged artists, designers and citizens to transform metered parking spot into temporary public parks for a day (Edmonton, 2018). Edmonton's CITYlab can be seen as a model example as to how tactical urbanism can be used as a tool to drive change within communities, but to also create a sense of place in them as well. 


\section{Gaps in the Literature}

The suburbs are the product of the postwar housing growth, they are characterized by large properties encompassing single detached homes with ample yard space, that are auto dependant (Nijman, 2015). Luka \& Trottier (2012) suggest that attempts to retrofit suburban areas must take into consideration what makes them attractive to suburbanites, and that if this is not done they will be doomed to failure. There has been much discussion and research surrounding the suburbs and how to fix them, especially surrounding public spaces and underutilized spaces. One of the strategies that is starting to surface in the suburbs is the idea of tactical urbanism (such as in Edmonton, through their CITYlab initiative). In the right conditions tactical urbanism could be applied in some suburban settings as a tool to drive change within communities.

Tactical urbanism might be more challenging to apply in a suburban setting, however, it could also be a creative and inexpensive way to bring about incremental change in the many vacant or underutilized spaces in the suburbs (Mould, 2014). Nemeth \& Langhorst (2013), argue it can act as a way to increase vibrancy and community engagement. Scholars tend to argue that tactical urbanism acts as an effective short term solution to adding vibrancy and increasing social interaction within urban areas, this same conclusion could potentially be made about suburban cities and neighborhoods as well. As mentioned in the preceding paragraphs in order for tactical urbanism to work effectively, the ideal conditions required are densely populated areas that are walkable. One of the main challenges in the suburbs is the auto dependent nature and often lack of walkability. Spaces can become underutilized or disconnected due a lack of walkability or proper connections. When people are able to walk within their communities, they are more clearly able to identify any improvements that could or need to be made to their neighborhood or city. To this end, tactical urbanism can be applied in the suburbs in a similar manner to that of urban areas however, it might require a little more creativity. Such as, the Edmonton example. The Edmonton CITYlab is a body/organization that solely focuses on tactical urbanism like interventions, this model should be exemplified as a means to implement tactical urbanism in the suburbs. It is important to identify, lack of walkability and auto-dependency as barriers to the effective implementation of tactical urbanism in the suburbs, to then be able to move forward with creative measures to overcome these obstacles. 
There is a lot of literature available focused on retrofitting the suburbs more broadly. Some great work has been completed by Dunham-Jones \& Williamson which offers a number of ways to improve the suburbs in their book Retrofitting Suburbia: Urban Design Solutions for Redesigning Suburbs (2011). In this book they highlight some ideas such as encouraging adaptive reuse, intensification, increasing walkability, restoring green space and parks etc. (Dunham-Jones \& Williamson, 2011). It seems that there is a bit of a gap in the amount of literature available on tactical urbanism with a suburban focus, specifically with a Canadian focus. Therefore, this paper strives to use Brampton, Ontario as a case study to test tactical urbanism in the suburbs through the observation of a tactical urbanism project conducted in the form of a laneway transformation (McArter Lane). This observation and the literature collected on tactical urbanism in urban areas will inform the discussion on how the concept of informality can be used in the suburbs as a means to improve and show the public that underutilized areas can be greats spaces once again. 


\section{Methods}

Tactical urbanism is an alternative method to formal planning practices, using a short term model, scarce resources and citizen involvement to drive change within neighborhoods (Silva, 2016). To grasp an understanding of Tactical Urbanism and how this can be used by municipalities, specifically suburban cities, primary research was collected in the form of observation. One laneway was assessed in Downtown Brampton, Ontario; McArter Lane. The laneway was observed as is, to assess the conditions, usability, pedestrian flows, and any other relevant information. Photos were taken of the laneway to offer the reader a better understanding of what each laneway looks like. One tactical urbanism transformation was carried at McArter Lane.

The tactical urbanism transformation occurred at McArter Lane in downtown Brampton on Saturday November 4 ${ }^{\text {th }}, 2017$ from 7am-4pm. The City of Brampton's Planning Department funded and implemented the transformation. As a working employee with the city of Brampton this offered a unique advantage to the tactical urbanism project. The procedure and logistics of the project was discussed over internal meetings, as well as, a proposal for the project was presented to council (See Appendix A). The proposal was originally for the transformation of 4 laneways, but only one intervention was executed. In meetings, information such as, what the transformation will look like, the materials needed, the placement of furniture and objects, giveaway items etc. was discussed. Only, information pertaining to the scope of the project was acquired through meetings at the City of Brampton's Planning Department. It is important to note that only observable data was collected during the laneway transformation. Observable, unobtrusive, non-participant information/data was collected while at the tactical urbanism transformation. Some of the information collected included how people interacted and participated with the space, general observable reactions, pedestrian flows, and any other relevant information.

The laneways were mapped out using Google Earth (2016), to provide the reader with context as to where they are located, along with a site analysis, to showcase the existing conditions of the McArter Lane. A brief policy review was conducted to highlight some of the challenges inhibiting Brampton from implementing short term changes or solutions. The research is additionally supported with academic literature on tactical urbanism that helps provide an 
Tactical Urbanism Benefits and Constraints: A Brampton Case Study

understanding of tactical urbanism with a discussion on the benefits and constraints of implementing this tactic. 


\section{Brampton, Ontario}

Brampton is located in the province of Ontario in Canada. It is part of a two tier municipality, where the Region of Peel is the upper tier and the City of Brampton is the lower tier. Brampton is a suburban city characterized by larger homes with substantial property sizes, it is a car dependent city encompassing large road networks and highways. Brampton is a rapidly growing city, with a population of 593,638 people as of 2016 (Statistics Canada, 2017). Most of the growth in Brampton occurred in the 1980s and 1990s, where large low density subdivisions (typically semi and semi-detached homes) were developed on farmlands (The City of Brampton, 2018). Brampton is characterized by its large road networks, auto dependency, historical downtown and larger property sizes, features that are typical for suburban cities.

In attempts to improve the City of Brampton, the City is currently undertaking a visioning process. Brampton has hired world renowned Larry Beasley and his team of consultants to assist in this process. They have conducted numerous public engagement sessions to gain a deeper understanding of where residents see Brampton heading in the future, and what they want to see Brampton become. This vision will become publicly available in the Spring/Summer of 2018, it will entail all of the great ideas Brampton residents brought to the attention of the City. Once this plan is released tactical urbanism might be a tool or tactic the City may choose to implement to test or show the public how these ideas might work to gain support, and inspire residents to become engaged and encouraged continued conversations on how to continually improve the city. Brampton is a city that will be experiencing substantial change in the future due to the implementation of the Light Rail Transit line (LRT) down Hurontario Street, the construction of a Ryerson University campus, the development of the last remaining greenfield lands, and the implementation of the Planning Vision, upon the release of the Report. With all of this change occurring in the near future tactical urbanism might be a positive tactic to implement to help achieve the goal of improving the city.

\section{Brief Brampton Policy Structure}

Brampton operates under Ontario planning regulations, where the Planning Act is prime planning document and all other documents support and complement this Act. The City has an 
Official Plan that guides the development in the city, as well as, Secondary Plans, that break down the city into smaller sections, to offer a deeper focus on how the lands should be developed, while still keeping in mind the overarching ideas from the Official Plan. Each property is zoned, which gives specific designations that come with permissions which must be strictly followed. Any change to the city requires one to follow a number of different processes that range in various timeframes of completion, arriving at City Council (publicly elected officials) who offer their final vote to decide if the change should occur or not. When a proposal reaches Council, the preparation typically involves a proposal document, recommendation report, presentation or other materials to strengthen the case for the proposed change. Items can be deferred or new material can be requested, further lengthening the process. Thus in order to see change within the city it can often take years at a time. To this end, where possible tactical urbanism can be applied to potentially help support a proposal or application, offering a sense of urgency, and a real life example to support the change. 


\section{Results: Tactical Urbanism in Brampton}

The City of Brampton recently proposed to transform its laneways over the course of a weekend to display the possibility of change in these spaces to Brampton residents. This proposition included items and activities such as, removable street furniture, games, pop-up vendors, public art etc. Initially there were a total of 4 laneways that the City was looking to transform. Specifically, these laneways were located in the downtown area around the intersection of Main Street and Queen Street (Vivien Lane, McArter Lane, Harmsworth Lane and Buffy Lane) (see Appendix A). These laneways are seen as underutilized spaces in the City of Brampton that have the potential to be great spaces for everyone in the city to enjoy. As of now the laneways are typically used as pathways rather than anything more, which is why tactical urbanism was deployed to display the potential. Brampton's vision was and is to convert the laneways into areas the public can congregate and socialize. Although the original proposal was intended for the transformation of four laneways, due to budgetary constraints, limited remaining available dates, and the weather they narrowed the transformation down to one laneway, McArter Lane. Map 1, depicts the locations of the laneways in Downtown Brampton.

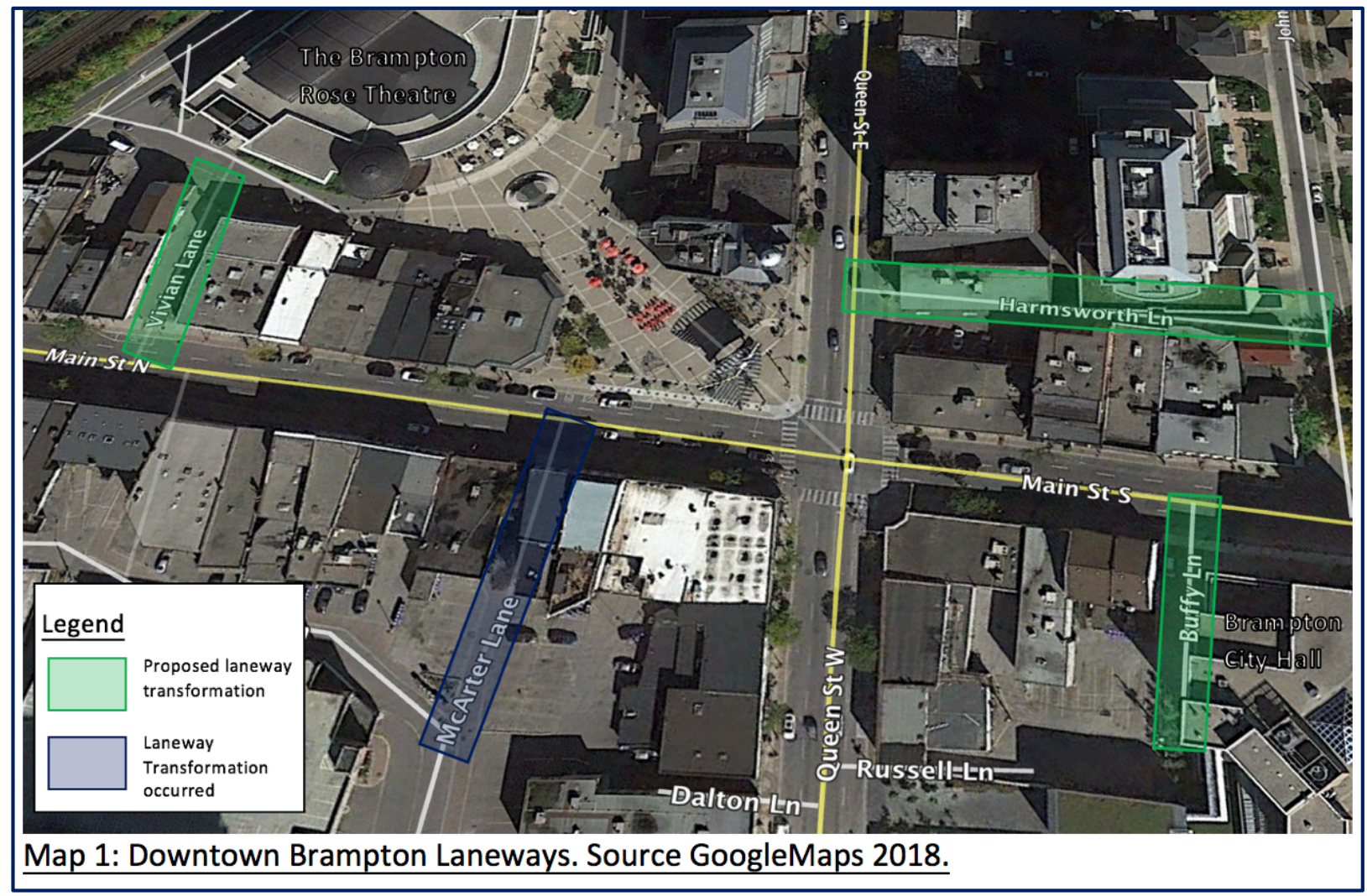




\section{Present Conditions of McArter Lane}

McArter Lane is located along Main

Street, North of Queen Street, South of Church

Street. The laneway is approximately 58 metres in length and connects Main Street North to Diplock Lane. It is a pedestrian only laneway situated between a historic building (Subway) and a clothing store. Diplock Lane encompasses a parking lot naturally enabling McArter lane to function as a pathway connection to Main Street. The laneway itself is underutilized with its primary purpose serving as a pathway for the movement and flows of people. There are no

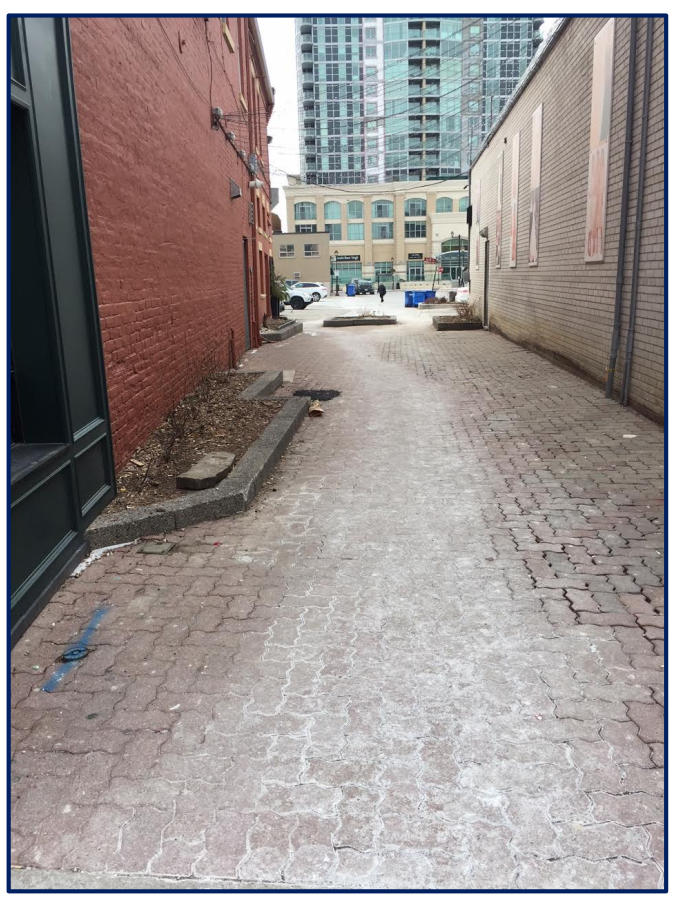
trees, within the laneway, they appeared to have been cut down, and there are just a few shrubs.

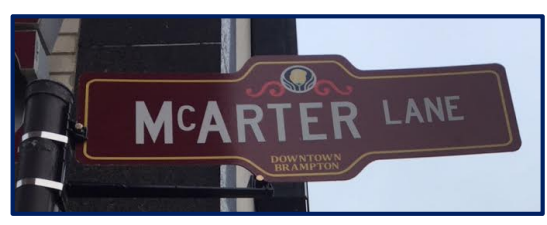

The pathway is made up of interlock red bricks. In addition, there are four sort of boxed off areas for potential planting, in the warmer months. It is a plain looking laneway, that lacks vibrancy and aesthetics.

\section{The Tactical Urbanism Intervention in Brampton}

On Saturday November $4^{\text {th }}$ 2017, The City of Brampton transformed McArter Lane in downtown Brampton. The intervention occurred in conjunction with the seasonal Harvest Market which runs on Saturday's from 8am-3pm. The Harvest Market stretches along Main Street from Queen Street to Church Street, throughout the Fall season. McArter Lane is located within this stretch and making it an ideal candidate to conduct the tactical urbanism intervention. 


\begin{tabular}{|l|}
\hline \multicolumn{1}{|c|}{ Items } \\
\hline 17 Plants \\
\hline 4 Tables \\
\hline 8 Chairs \\
\hline Candles \\
\hline Lanterns \\
\hline 6 Hay bales \\
\hline DJ \\
\hline Polaroid Camera \\
\hline Polaroid Photos \\
\hline $\begin{array}{l}\text { Magazines/ Reading } \\
\text { material }\end{array}$ \\
\hline 10 Umbrellas \\
\hline Pop-up Graffiti Art \\
\hline Chalkboard \\
\hline Sticky Notes \\
\hline $\begin{array}{l}\text { Free Coffee/ Hot } \\
\text { Chocolate }\end{array}$ \\
\hline $\begin{array}{l}\text { Free Environmental } \\
\text { Bags }\end{array}$ \\
\hline
\end{tabular}

Table 1: Items involved in the Intervention at McArter Lane
Set up began early at 7 am in the morning, which involved the placement of the transformation items within the laneway, Table 1 highlights the items used for the intervention. All items used for the were of a non-permanent nature, and were put up and taken down in the same day. The City ordered twinkle lights that were placed overhead from the two buildings which were set up in advance of the laneway transformation. Items were placed in the laneway based on a prepared vision for the laneway determined during internal meetings at the City of Brampton's City Hall. Plants, hay bales, candles lanterns and removable street furniture was placed within the space to liven it up. A DJ attended the event and played music in the laneway to add

vibrancy. In addition, the City offered Free Coffee and

Hot Chocolate as a thank you for all the input residents
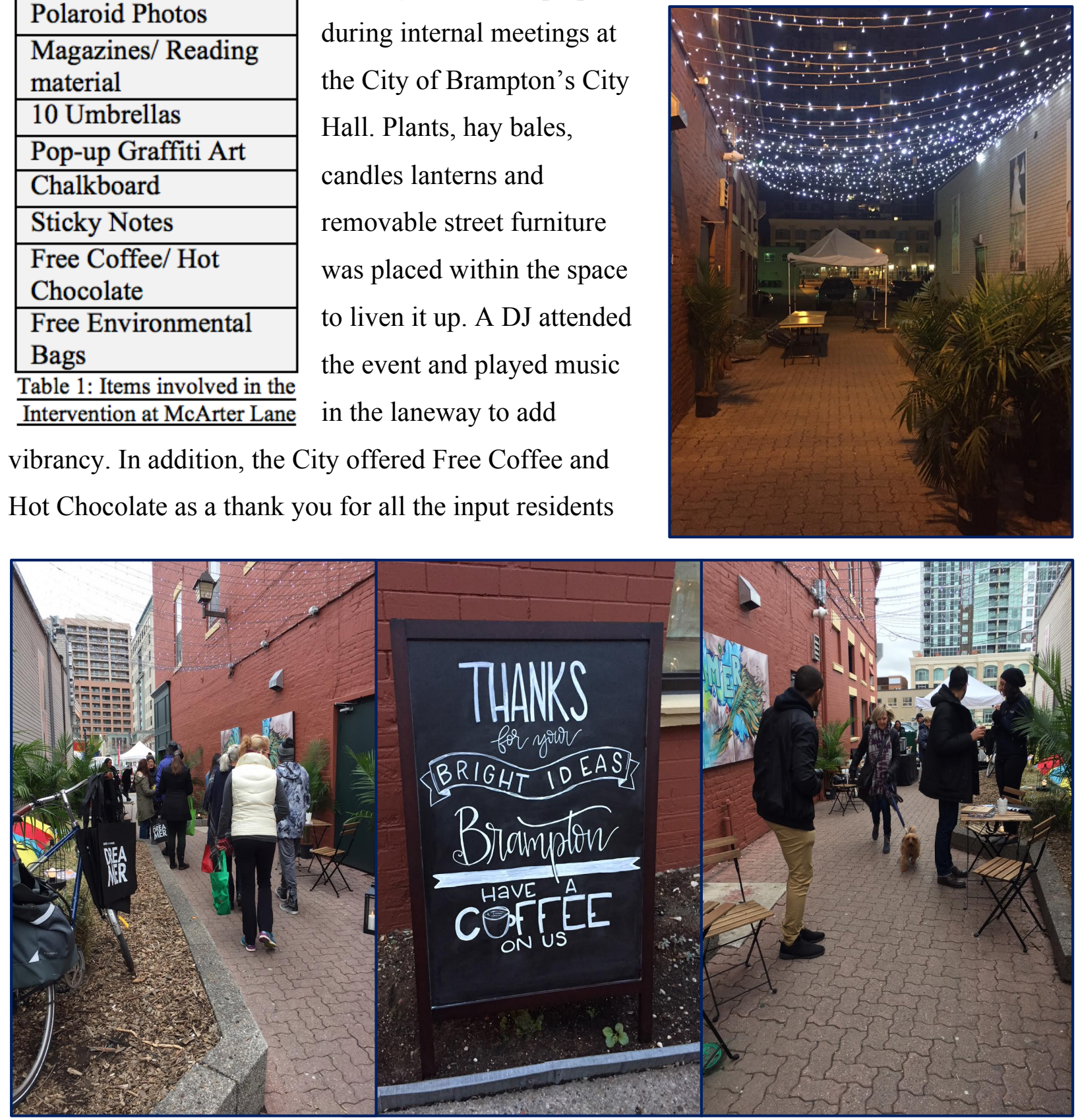
had provided in the previous months at public engagement sessions. A chalkboard located at the entrance near Main Street read "Thanks for your Bright Ideas Brampton Have a Coffee on us" which encouraged and generated more traffic flow. People seems delighted to receive a free coffee especially since it was a cold day.

The City offered free environmental bags to people passing through, which was well received by the public who were typically entering or leaving the Harvest Market. Another activity that was available to engage residents was a polaroid camera where people could take photos under the art display; some took the photo home and some hung up their photos in the laneway. Coloured

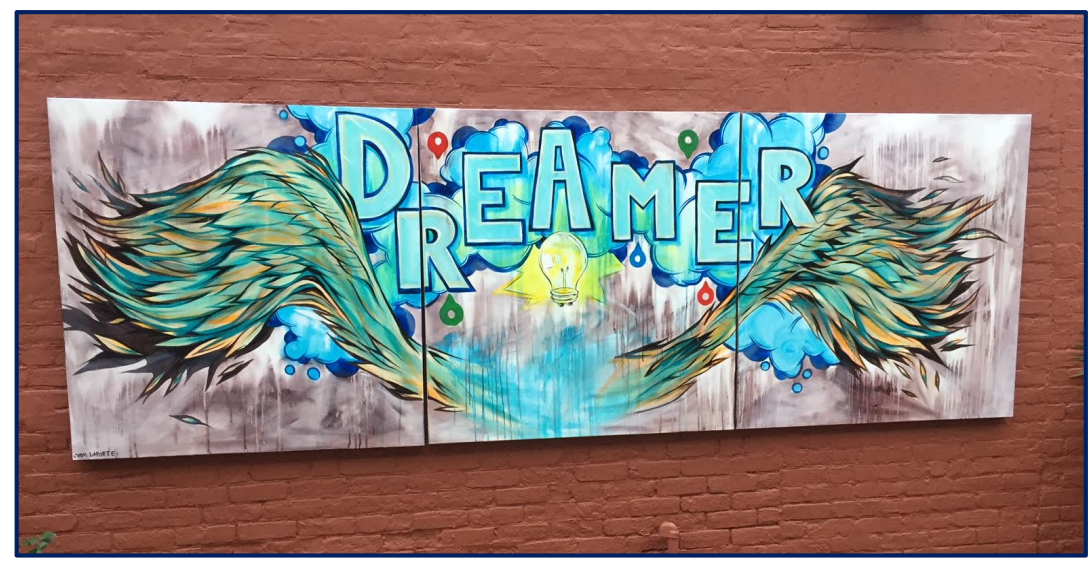
umbrellas were placed along both sides of the laneway to add pops of colour.

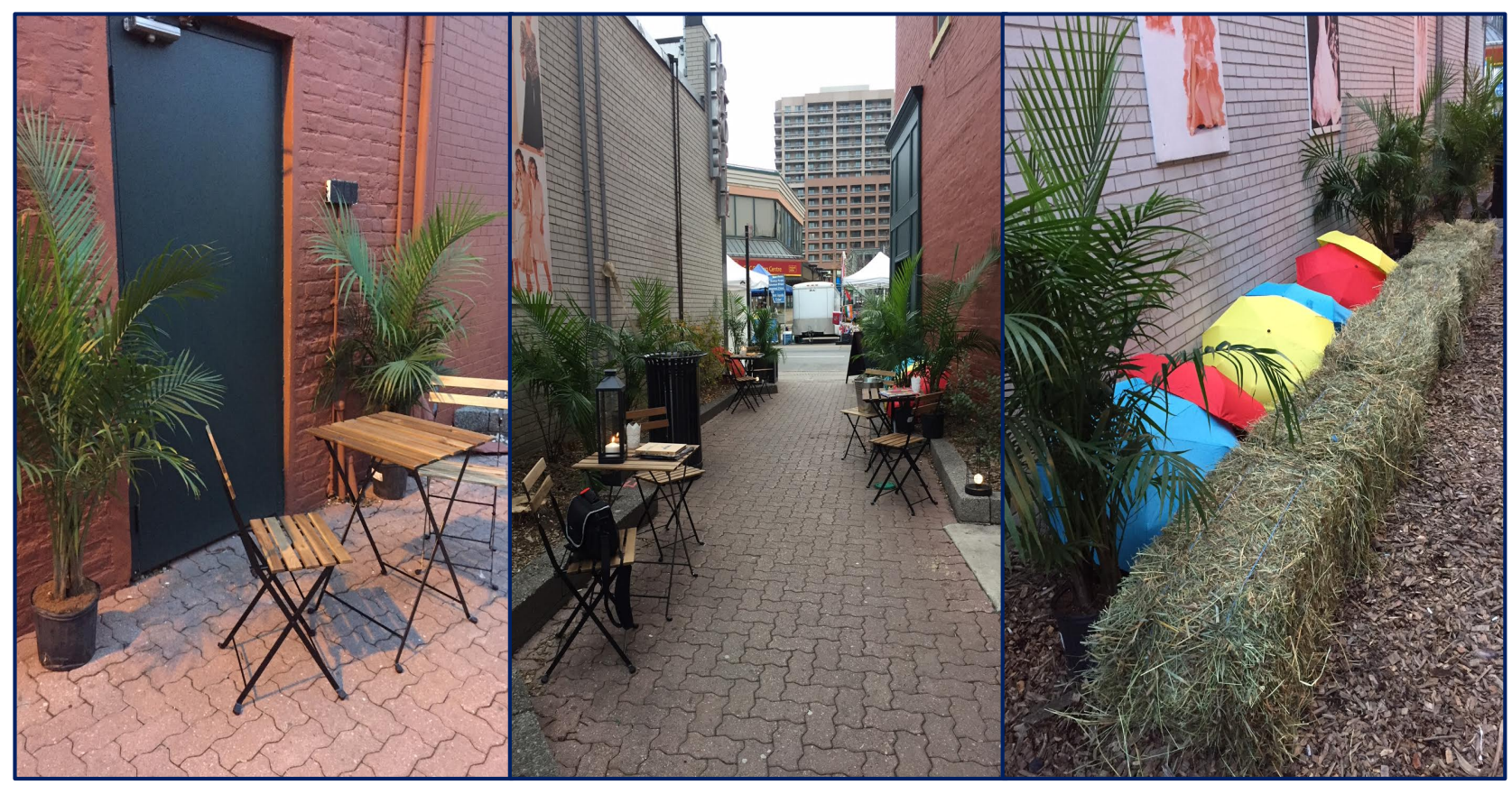

From an observatory role, people generally seemed enthused by the transformation, some sat at the tables and enjoyed their coffee. Others interacted with activities (taking pictures, listening to the music, socializing etc.). The Harvest Market generated a lot of traffic flow, 
roughly between 800-1000 people walked through the laneway, some just passing through while others engaged with the space. The City of Brampton created a hashtag for people to post their photos in the laneway on Instagram, Twitter and Facebook. Only a select few (16 people on instagram) posted their personal photos using the hashtag. They posted pictures under the public art, the Polaroid photos they took and the new scenery.

Observations were also made when residents were interacting with City of Brampton employees, City employees informed residents why the intervention was taking place, thanked them for their participation in the engagement sessions for the visioning process, and had conversations regarding what they liked about the transformed space. Most people were curious as to what was going on and why this was happening. Some people seemed to wish the space could permanently stay this way, and wondered how to make that happen. While others just walked through with a sense of excitement and enjoyment of the transformed space. The intervention ran from $8 \mathrm{am}-3: 30 \mathrm{pm}$, when the transformation was over all the materials were easily taken down and the laneway was restored to its original state.

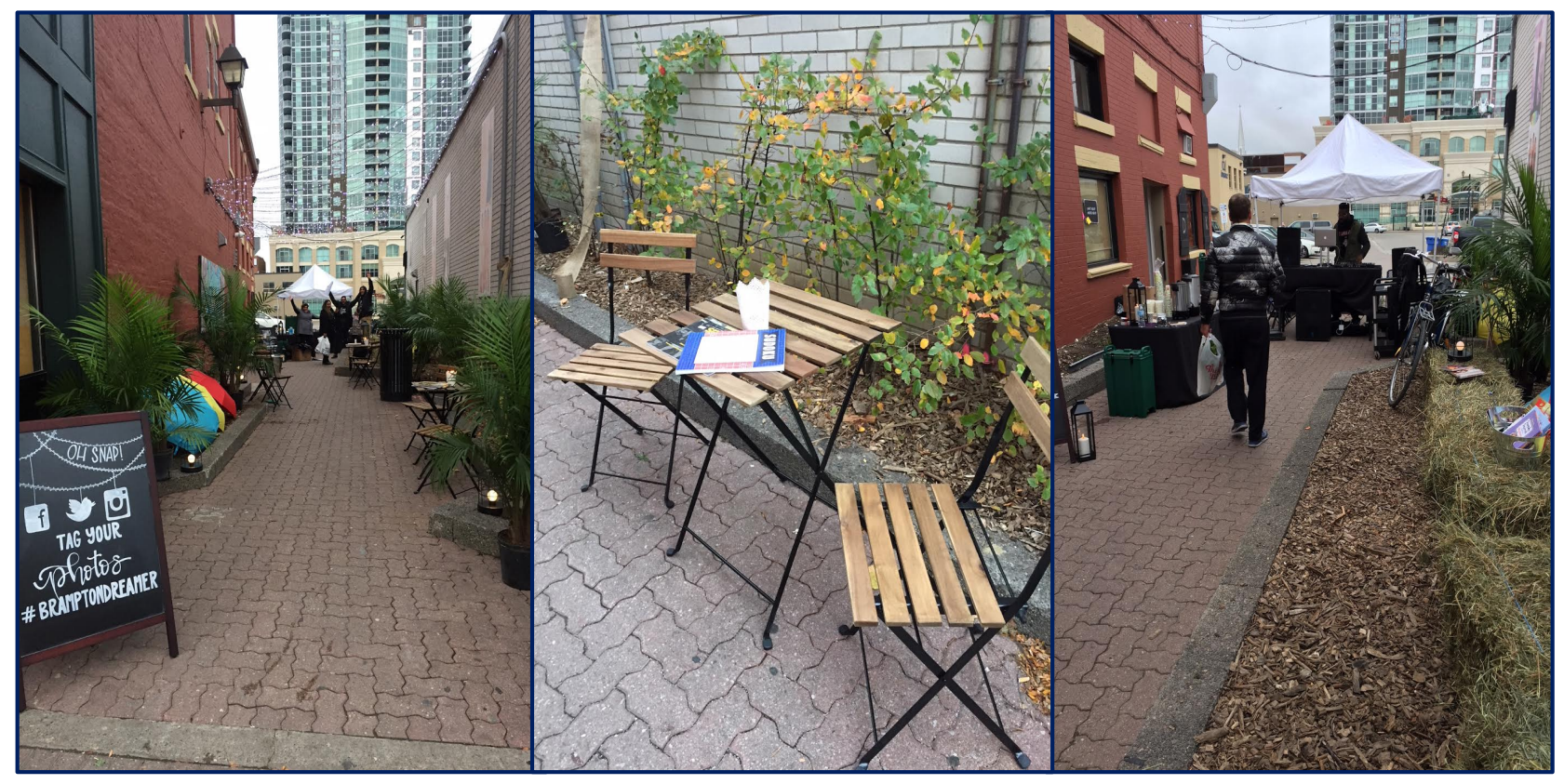




\section{Discussion}

Overall the transformation of McArter lane was successful in attempting to display the potential of this underutilized space and what it could be in the future. The intervention offered a unique opportunity to display the positive effects the laneway could have for the neighborhood through a temporary transformation, that was assembled and disassembled within the same day. It showed the potential of the space through a short term solution rather than the waiting, that is often involved in the traditional planning process. This can now be used to support future interventions and drive change within the laneways in Downtown Brampton. The literature highlighted some benefits and constraints of tactical urbanism, which can be applied and displayed in the case example of Brampton.

\section{Benefits of the Tactical Urbanism Intervention}

As identified in the literature, there were three main benefits, the not permanent nature, urban politics and funding and community involvement and increased participation. All of these benefits can be seen in the Brampton case example. The literature mentions, tactical urbanism offers a unique opportunity to change the normal without making alterations that will harm or mark the space permanently (Silva, 2014 \& Lydon \& Garcia, 2015). The transformation in McArter lane was not permanent, and all items and objects were completely removable, making this laneway transformation particularly attractive to the City of Brampton. The City did not have to commit to a long term solution, there is no long term maintenance associated with the intervention or complications.

As mentioned in the literature, the politics involved or lengthy processes that must be followed to pass or create policies and alterations within a city inhibits one's ability to drive change. This type of intervention allowed the City to by-pass processes typically involved in the traditional planning model. As noted in the Brampton policy section of this paper, implementing change within the city can often be a lengthy process, to this end, this intervention was carried out as a short term solution, that can now be used as a way to support change in the Downtown. Pictures were taken and residents participated, this can be used in a formal proposal to council if 
necessary. Brampton residents use McArter Lane regularly, some might contemplate how the space could be improved and some might not think twice about it. The successful application of this tactic allows and aids policy makers, planners, and other various stakeholders the opportunity to showcase the potential for a space and drive change to implement a temporary intervention into a more permanent alteration. It allowed the public to reimagine the space and start to think about other spaces within their neighborhoods that could follow a similar model. It additionally, allowed residents to physically see the change rather than conceptualizing what the laneway could look like. Conceptualizing what a space could look like is often what happens in public engagement sessions, rather than being able to physically seeing the change in person.

Lastly, this intervention allowed for increased community involvement and participation in the planning process. Implementing a pop-up in a space that is regularly used by residents is an excellent way to get the community involved, by just partaking in their regular routine. For example, the initial impetus for passing through the laneway was likely to visit the Harvest Market, therefore, residents are not taking time out of their busy schedules to participate in the transformation or attend a public meeting, but rather they are interacting with the space they were already going to engage with. Through this interaction the space generates buzz and it creates a further conversation about a new potential for the area, and might encourage the community to engage in future interventions or demand a change be made in their neighborhood.

\section{Constraints Associated with the Tactical Urbanism Intervention}

The literature identified three main constrains associated with tactical urbanism which can also be displayed through the case example these include; challenges of urban politics, selforganizing initiatives and scale. This was the very first "recorded" formal tactical urbanism project in Brampton. One of the issues that could arise in the future, is that residents might take it upon themselves to orchestrate tactical urbanism transformations. While this can be seen as positive step that residents want to improve their neighborhoods, it can also be seen as a threat to the Corporation of the City of Brampton. This is because if something goes wrong during the intervention it is unclear who is liable. To this end, as scholars suggest maintaining public safety, balancing equity concerns, consensus, efficiency, coordination of urban systems and more are important aspects that need to be considered and prioritized when it comes to the temporary uses 
of space (Finn, 2014; Iveson, 2013). Concerns such as these may lead the City to restrict future interventions and therefore this will restrict and impact future creativity and a community's ability to drive change within their neighborhood. However, since this is the first recorded transformation, this concern is yet to be expressed, but there could be a future concern and this could lead to policing or monitoring of tactical urbanism projects.

One of the other constraints that has come out of this transformation is there has not been a continued conversation on how to improve the laneways in the future. When the intervention was occurring back in early November 2017 it generated buzz, the transformation was fresh in people's minds, and people wanted to see this change occur. Since then the conversation has mellowed down, and at this time nobody is championing the ideas implemented that day. There are currently a select few of employees at the City of Brampton who want to make changes and champion this idea, but do not have enough time or resources. It is the hope of these employees that in the near future something can be done about this. Through this example it became evident that despite the positive feedback and buzz the intervention generated, there is some difficulty with the short term nature of the project. It became a challenge, to actually force and encourage policy makers and the public to drive the change, whether that be through voiced opinions or through policy changes. To this end, the politics and lengthy processes once again impede on the ability to create and implement change.

Lastly, the literature highlighted that these initiatives tend to be self-organizing, whether it be community members, interested stakeholders etc. This particular intervention was carried out by the municipality, and while this is a very positive and forward measure implemented by the City, the City might not always have the time or resources to execute a project of this nature. To this end, it is hard to motivate or expect the public to initiate tactical urbanism within their communities. This intervention occurred in downtown Brampton by the City, it's hard to know or gauge how motivated the public was by this transformation or if they will ever consider doing something similar in their own neighborhoods, which might not necessarily be in the downtown. It might be too early to tell how this impacted the public formally, since this transformation occurred in November, 2017 it is possible the City could potentially see other transformations occur in various neighborhoods across Brampton in the warmer months. 


\section{Recommendations}

After assessing the benefits and constraints of tactical urbanism using Brampton as a case example a few ideas could be brought forward to potentially aid future tactical urbanism projects, or help to further this research.

The first idea being, the City should consider hosting more interventions in other areas of the city, not just the downtown. Residents have seen how this type of project operates, photos have been taken, it's been advertised in the past and now the City can use this momentum to build off of. More frequent tactical urbanism projects will generate buzz and conversations on how to improve any spaces perceived by either the public or the City as spaces in need of improvement or change. Any future projects do not necessarily have to occur in laneways, but rather they can happen in any underutilized spaces within the city.

A second idea involves engaging the public to take initiative in tactical urbanism projects. As mentioned it is understood that resources are scarce, thus the City can potentially address this in two ways. The first, engage in public-private partnerships, or collaborate with organizations who have an interest in improving the city or specific neighborhoods within Brampton. The second way the City could further encourage informality is through hosting evens such as those conducted by Edmonton's CITYlab. These could include days where the public transforms onstreet parking spaces, parking lots, parks or other spaces within the city. It would be advertised by the City of Brampton but the time and resources would mostly fall on the residents to carry out on those days.

One more thing the City could to do encourage residents to take charge in their communities is through education. Educate the public at events such as the Harvest Market, or other Brampton hosted events on the potential to improve spaces in their communities or neighborhoods. This could simply involve hosting a table at an event with photos from past interventions and answering questions or concerns. The City could ask questions such as do you have any spaces within your neighborhood that an intervention such as tactical urbanism could showcase a new potential? This would hopefully get residents thinking about how they can improve their own neighborhood and might encourage them to engage in their own self-initiated projects. 
Lastly and arguably the most important, the City could implement a similar structure to the CITYlab in Edmonton, which was briefly discussed in the literature review section of this paper. The CITYlab can become an avenue to implement short term solutions to planning issues within a city such as, conducting tactical urbanism interventions. The CITYlab would advertise events that might encourage community members to assess their neighborhoods and aid in changing the City, through temporary projects, initiatives, and tactics. The CITYlab would encompass a team of passionate advocates for the City (planners, policy makers, students etc.) who would collectively deliberate creative solutions for the City, and think of ways to actively involve the community. For example, they could use technology as a means to advertise future tactical urbanism interventions within the city. A mobile application could be developed that would allow community members to advertise their tactical urbanism projects, increasing community awareness and traffic flow to these sites. The CITYlab could develop partnerships with organizations and interested stakeholders to offer a more effective approach to implementing change. Partnerships could be with local organizations with a particular interest in improving the city, it could be partnering up with institutions such as Sheridan College or Ryerson University (both either will or are already located in Brampton) and more. Furthermore, The CITYlab could also aid in implementing some of the guiding principles or actionable items that emerge out of the Planning Vision document once this is released. This recommendation would involve a select few people to really champion this idea, and to really try to excite, educate and persuade the City of Brampton that a CITYlab can be extremely advantageous for the City. Of all of the recommendations, the notion that somebody needs to champion a CITYlab or innovation type body seems to be the most important as it would ensure and secure that the future of tactical urbanism remains bright.

\section{Next Steps}

Moving forward, the City of Brampton should try to formulate a CITYlab structure or something of its equivalence. A first step would be establishing a group of individuals who will champion this idea. This needs to be a strong set of individuals who will persevere through any obstacles and continue to be positive in finding a way to get this implemented. A second step might entail calling Edmonton's CITYlab or another CITYlab type structure and asking questions such as; how they started, who championed the project, how did they gain support 
Tactical Urbanism Benefits and Constraints: A Brampton Case Study

from their staff and council, any barriers they experienced getting this project off the ground and any helpful information that could aid in the successful implementation of a CITYlab structure in Brampton. Once some research has been collected on how other municipalities managed to get a project such as this off the ground is obtained, this might provide a clearer picture on what tasks need to be done moving forward. 


\section{Limitations}

It is important to note that, there are a few limitations to this research and findings. The first being the intervention only occurred at one laneway in Brampton, rather than a number of different spaces, across various municipalities. The laneway is located in downtown of Brampton which mimics an urban like setting, potentially attributing to the much of its success.

Additionally, the intervention occurred in conjunction with the Harvest Market which generated a lot of foot traffic through the laneways. Lastly, the weather on the date of the intervention was cold and could impacted the engagement with the laneway transformation. The results could have differed slightly if the intervention occurred in warmer conditions. 


\section{Conclusion}

After an assessment of the benefits (non-permanent nature, urban politics, increased resident participation and community involvement) and constraints (challenges in urban politics, scale, and self-organizing initiatives) of tactical urbanism. Through the use of Brampton, Ontario as a case example to apply to these concepts identified in the literature, it can be determined that it is a creative and short term solution to drive change within communities and neighborhoods. While this is not a perfect tactic, the benefits that steer this method away from the traditional planning model, makes this an attractive model for any stakeholder interested in driving change within their community.

The following are some key recommendations to consider when implementing future tactical urbanism projects in Brampton; increase the number of interventions in various communities throughout Brampton, ensure that future interventions occur, engage the public to encourage self-organized initiatives, educate the public on what tactical urbanism is, and implementing a CITYlab like structure in Brampton. Using tactical urbanism as a means to drive change is still in its early stages in the City of Brampton and while all signs point to this being an effective method to drive change, no method is perfect and improvements can always be made. This research could be furthered in the future by conducting or observing multiple interventions and the impacts on urban planning tactical urbanism has over time. This would allow for the assessment and understanding as to how effective the tactic really is, and to determine if in fact this short term model will result in the desired policy changes or permanent changes within communities or neighborhoods. 
Tactical Urbanism Benefits and Constraints: A Brampton Case Study

\section{Sources}

Bishop, P., \& Williams, L. (2012). The temporary city. New York: Routledge.

Donovan, F. (2014). DIY urbanism: implications for cities. Journal of Urbanism. Vol 7 (4), 381 398.

Dunham-Jones \& Williamson (2011). Retrofitting suburbia: urban design solutions for redesigning suburbs. Hoboken, New Jersey: John Wiley \& Sons.

Edmonton. (2018). CITYlab. Retrieved from: https://www.edmonton.ca/city_government/initiatives_innovation/citylab.aspx.

Francis, J., Giles-Corti, B., Wood, L. \& Knuiman, M. (2012). Creating sense of community: the role of public space. Journal of Environmental Psychology. Vol 32, 401-409.

Google Earth V 7.3.1.4507. (November 9, 2016). Brampton, Ontario. 43 41'07.80”N, 7945'33.82’'W. Eye alt 579 metres. DigitalGlobe 2016. http://www.earth.google.com. [February 5, 2018].

Iveson, K. (2013). Cities within the City: Do-It-Yourself Urbanism and the Right to the City. International Journal of Urban and Regional Research. Vol 37(3) 941-956.

Luka, N., \& Trottier, L. (2002). In the Burbs: It's time to recognize that suburbia is a real place too. Alternatives Journal. Vol 28 (3), 1-5.

Lydon M. \& Garcia, A. (2015). Tactical Urbanism Short-Term Action for Long-term Change. Washington, DC: Island Press.

Lydon M, Bartman D, Garcia D, Preston R, \& Woudstra R. (2012) Tactical Urbanism 2: Shortterm Action, Long-term Change. Miami: Next Generation of New Urbanists

Lydon M, Bartman D, Khawarzad R, \& Woudstra R. (2011) Tactical Urbanism 1: Short-term Action, Long-term Change. Miami: Next Generation of New Urbanists.

Mould, O. (2014). Tactical Urbanism: The New Vernacular of the Creative City. Geography Compass. Vol 8 (8), 529-539.

Mukhiia, V., \& Loukaitou-Sideris, A. (2014). The Informal American City Beyond Taco Trucks and Day Labor. Cambridge, Massachusetts: The MIT Press.

Nemeth, J., \& Langhorst, J. (2013). Rethinking Urban Transformation: Temporary uses for vacant land. Cities. Vol 40, 143-150

Nijman, J. (2015). North American Suburbia Influx Introduction. Environmental and Planning A. Vol 47 (1), 3-9.

Silva, Paulo. (2016). Tactical Urbanism: Towards an evolutionary cities' approach?. 
Tactical Urbanism Benefits and Constraints: A Brampton Case Study

Environment and Planning B: Planning and Design. Vol 43(6). 1040-1051.

Statistics Canada. (2017). Census Profile: Brampton, City [Census subdivision], Ontario and

Ontario [Province]. Retrieved from: http://www12.statcan.gc.cal

Talen, E. (2014). Do-it-Yourself Urbanism: A History. Journal of Planning History. Vol 4 (2), 135- 148.

The City of Brampton. (2018). Brampton History. Retrieved from: http://www.brampton.ca/EN/Arts-Culture-Tourism/TourismBrampton/Visitors/Pages/BramptonHistory.aspx. 
Tactical Urbanism Benefits and Constraints: A Brampton Case Study

Appendix A

\section{CITY OF BRAMPTON}

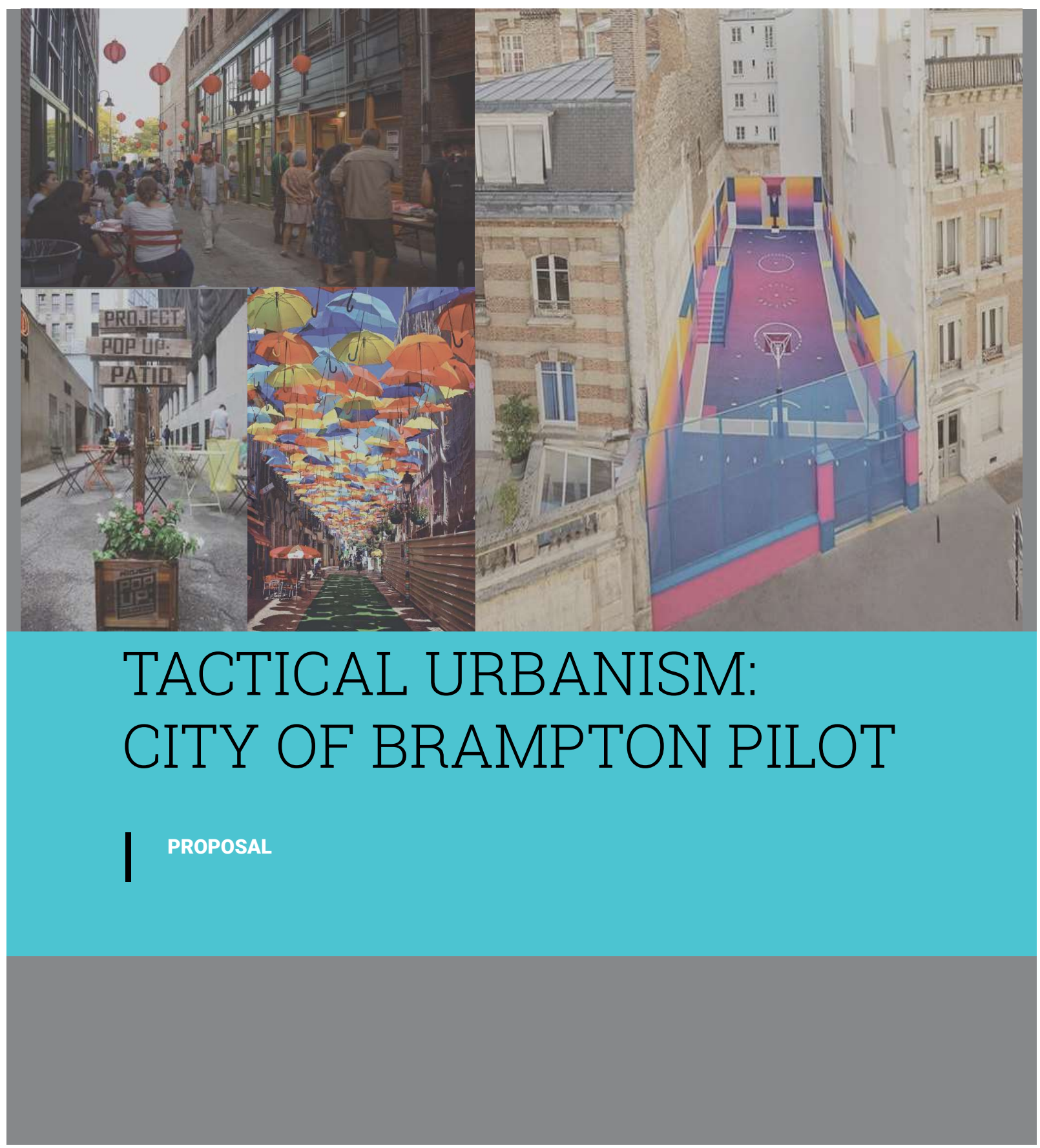




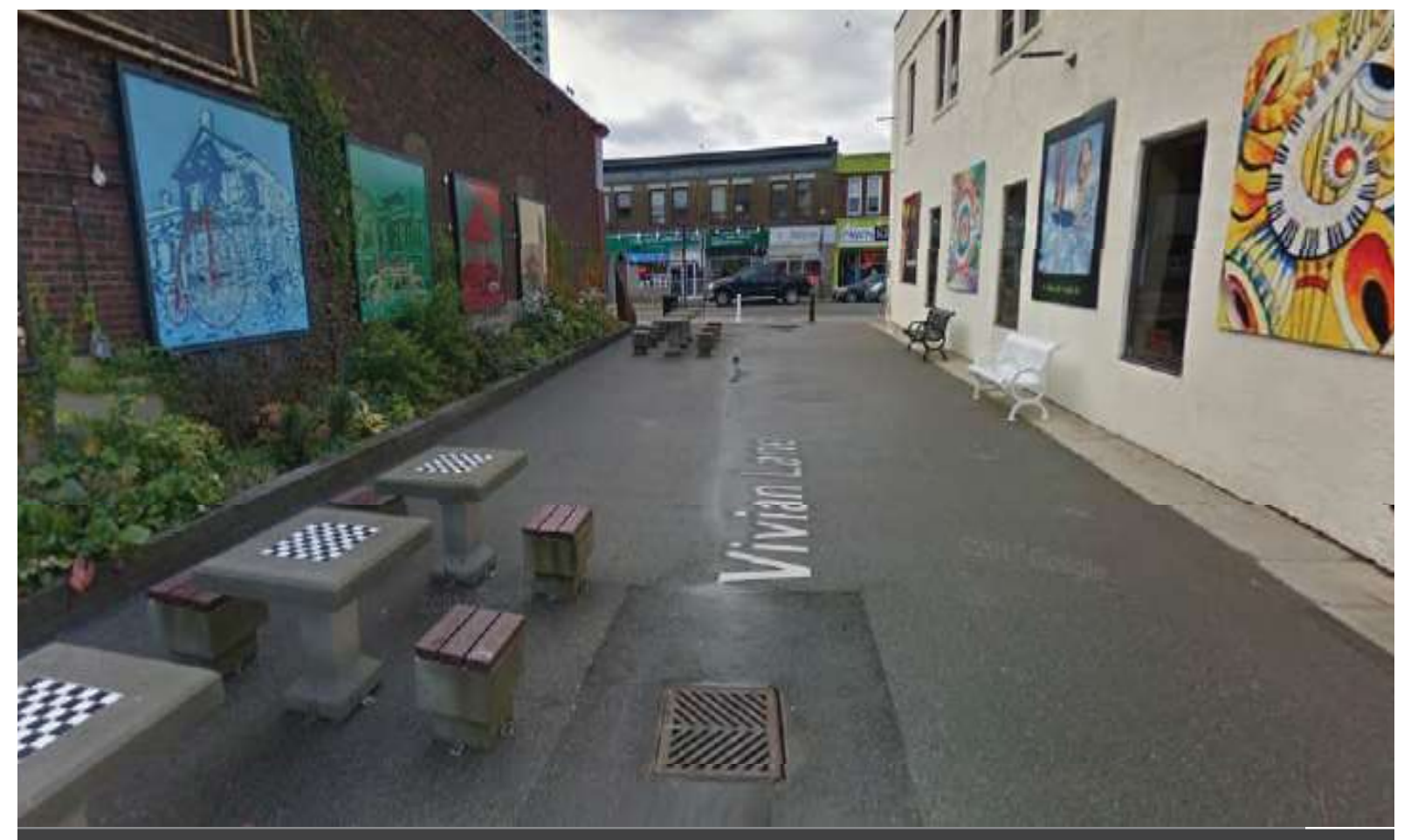

\section{SITES OF UNTAPPED POTENTIAL}

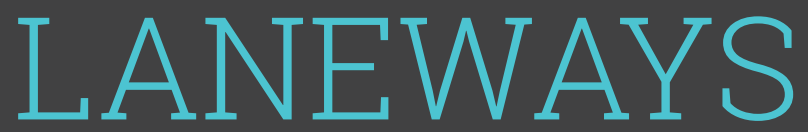

The City of Brampton has several laneways throughout the downtown and other areas of the city. These spaces are brimming with untapped potential, but at present they are underused, undermaintained and under-appreciated: they are not thought of, nor are they functioning, as complete parts of our public realm.

When planned and designed effectively, laneways can be a key asset and an integral part of the public realm of our growing and intensifying city. Laneways can provide extensive cultural, economic, social, health and environmental benefits to our neighbourhoods and to the city at large.

This will effectively be attempted through tactical urbanism. 


\section{TACTICAL URBANISM}

"is an umbrella term used to describe a collection of low-cost, temporary changes to the built environment, usually in cities, intended to improve local neighbourhoods and city gathering places."

Laneways can play a role in creating engaging, lively and richly textured places by providing:

Increased

Walkability and

Connectivity

A Dense Network

of Public and Green

Space

New Space for

Informal Physical

Activity

New Patio Space
New Space for Community Events

A Canvas for Public Art and

Preformance

New Space for Pop-up Shops and micro-businesses 


\section{FARMERS MARKET}

\section{LANEWAY \\ PLAYWAY PROJECT}

The Downtown Brampton Farmer's Market runs every Saturday, 7am-1pm and hosts over 40 vendors that provide local producer based, Ontario grown, farm fresh fruits, and produce to the visitors and residents of Brampton. The Farmer's Market on average draws an average 3000-5000 visitors each weekend.

Currently there is one viable remaining date in 2017 to "disrupt" the built environment and engage the public: October 7 .

The Laneway-Playway Project will attempt to activate underutilised laneways in Downtown Brampton, during the Downtown Farmer's Market. This project will attempt to draw people from Main Street into the laneways to participate in various activities and answer various questions to benefit the development of the Planning Vision and Urban Centres

Gamechangers. Each of the identified laneways will be programmed with different park

typologies, and activity to spur discussion. 
Tactical Urbanism Benefits and Constraints: A Brampton Case Study

The project will focus on four of Brampton's prominent laneways.

\section{VIVIAN LANE - 1}

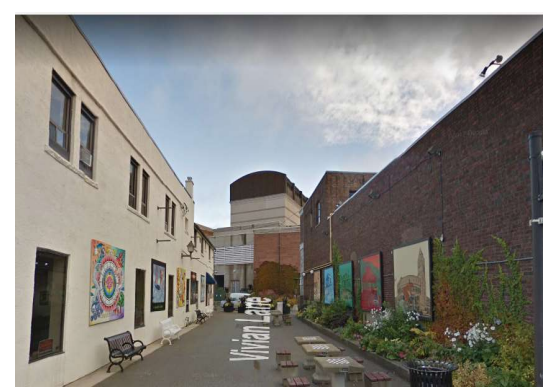

MCARTER LANE - 2

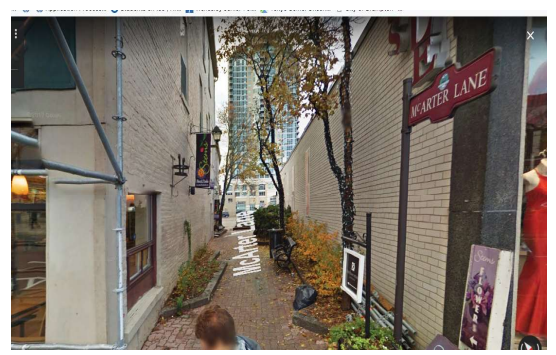

HARMSWORTH LANE - 3

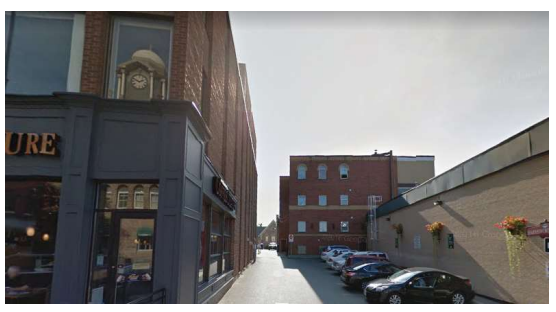

BUFFY LANE = 4

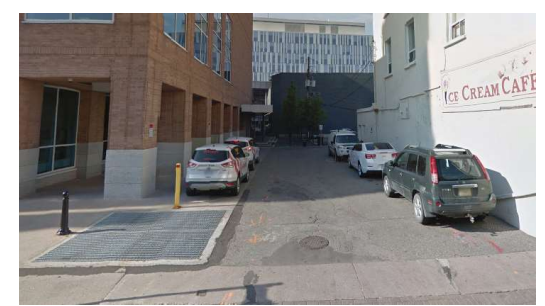


Tactical Urbanism Benefits and Constraints: A Brampton Case Study
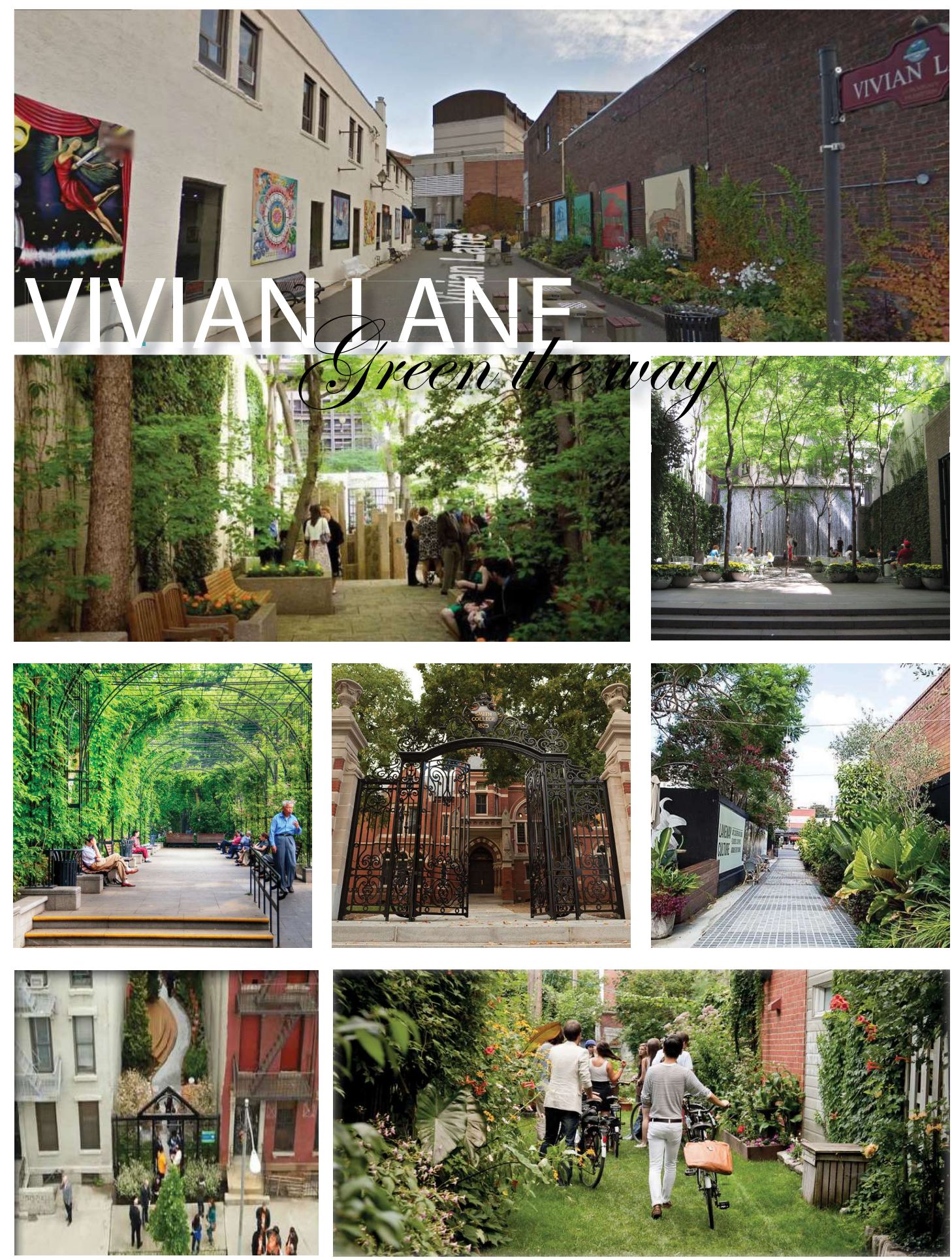

6 

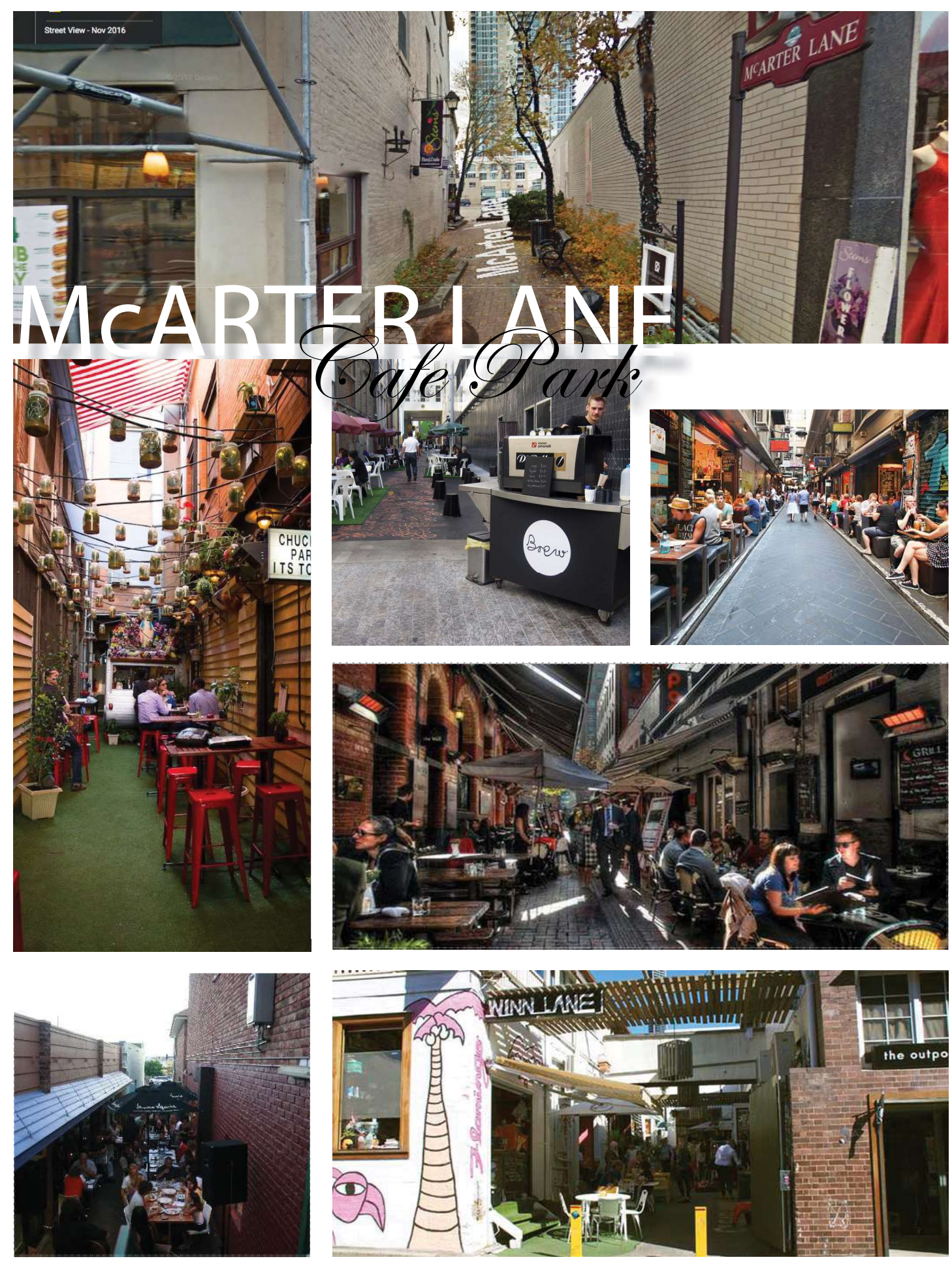

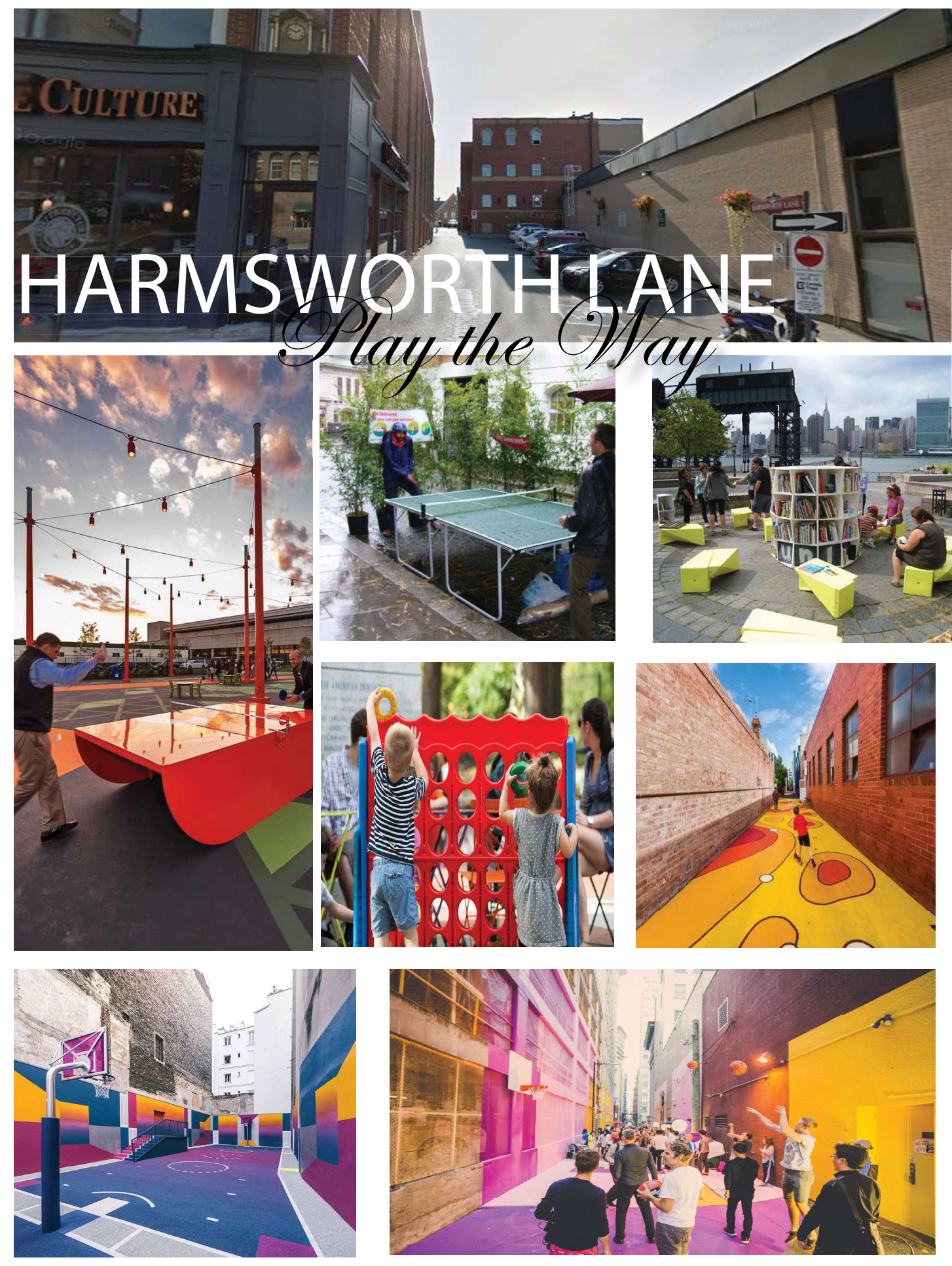

8 

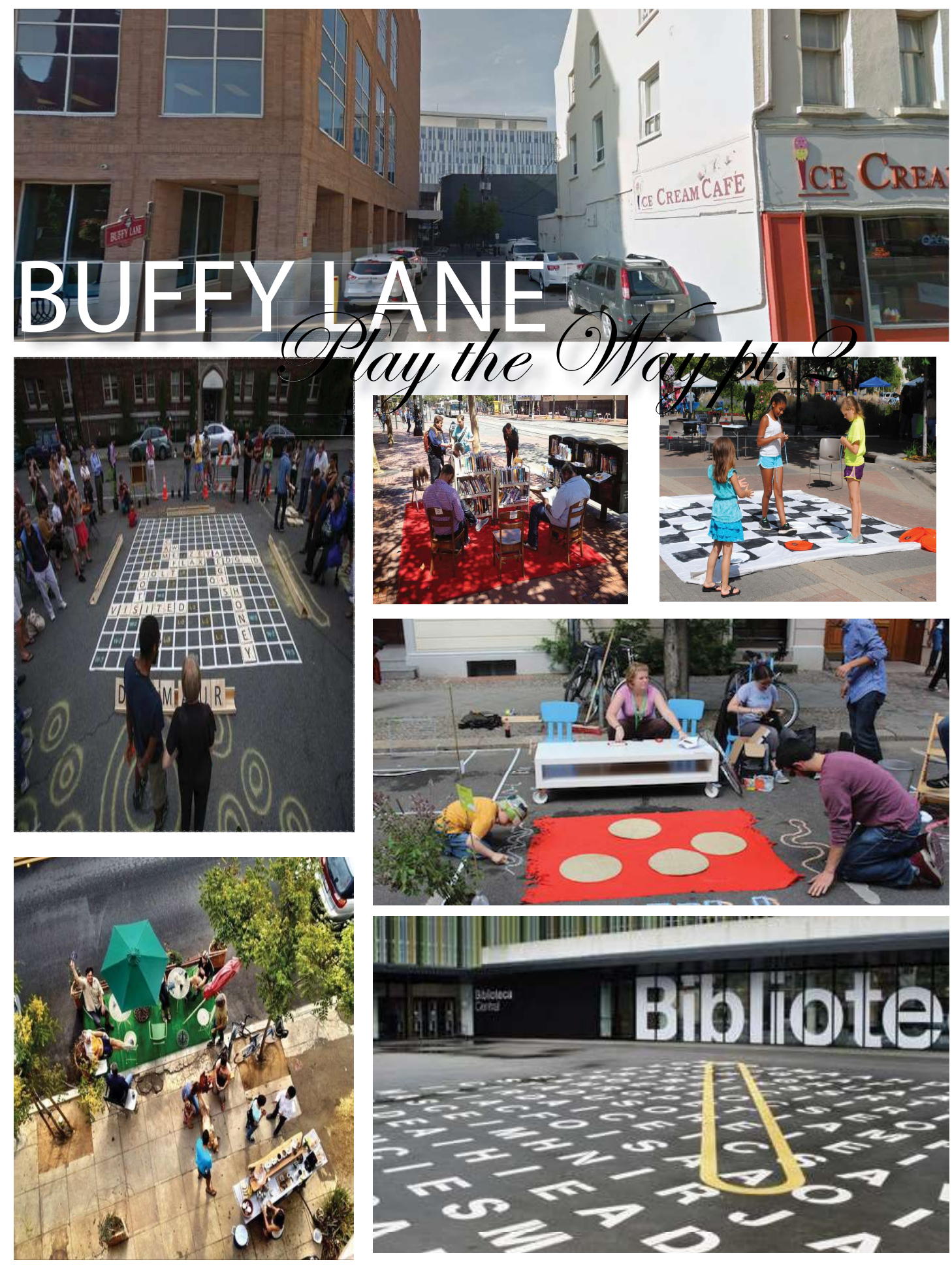


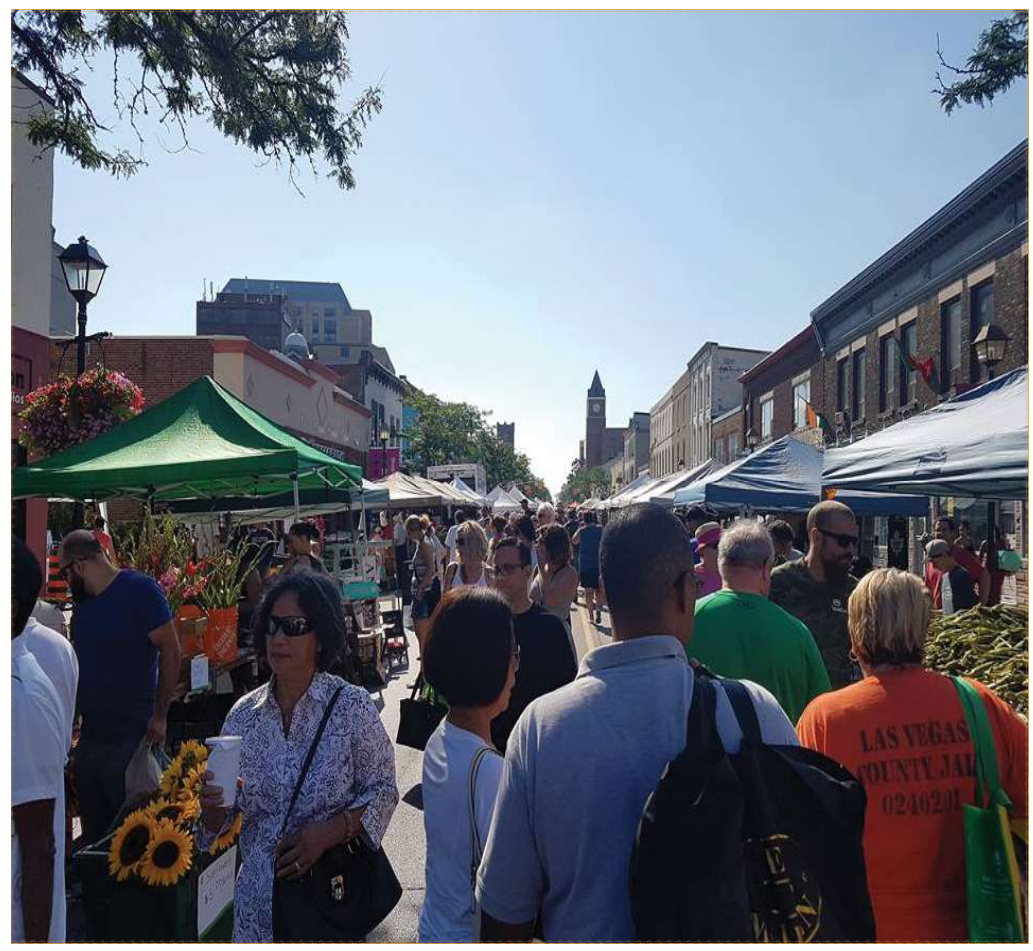

To encourage visits to each of these locations, creative means can be employed. A 'passport', for instance, could encourage younger attendees, alongside their parents to visit each laneway, to get a stamp. Once all stamps are collected, they could be rewarded with something from the market.
Ultimately, the purpose of this initiative is to demonstrate that life can be breathed back into these laneways and that space can be practically and functionally used. The activities proposed are intended to reach a wide demographic, from those who are able to physically participate in activity, to those who would rather passively participate. 